\title{
Effect of external hydraulic head on swelling of unsaturated clay
}

\author{
Shay Nachum ${ }^{1 *}$, Mark Talesnick ${ }^{1}$, and Sam Frydman ${ }^{1}$ \\ ${ }^{1}$ Technion, Israel Institute of Technology, Dept. of Civil \& Environmental Engineering, Haifa 32000, Israel
}

\begin{abstract}
Laboratory testing of the one-dimensional swell of soil (usually unsaturated clay) is generally performed according to ASTM standard D4546. The standard procedure requires that "the specimen is inundated with test water and the one-dimensional wetting-induced swell or collapse strain is measured". This procedure undoubtedly provides an upper limit to the swell which may be expected under field conditions, and may be relevant to cases in which low lying areas are expected to be inundated as a result of a wetting episode. However, in other cases, wetting of the soil may result from less extreme conditions - for example absorption of water from underlying, wetted layers, or soaking of the lower portion of a swelling layer and resultant upward wetting due to suction forces. The present paper describes a laboratory investigation of the effect of external hydraulic head on swell. The results demonstrate the importance of applying test conditions consistent with those expected in the field situation.
\end{abstract}

\section{Introduction}

Swelling or shrinking of unsaturated clay is a major cause of damage to structures and infrastructures worldwide. Jones and Holtz [1] estimated a yearly cost of $\$ 2.3$ billion in damages to houses, buildings, roads and pipelines in the USA. Wang [2] referred to data indicating a more updated estimate of $\$ 9$ billion in yearly damage due to expansive soils, with about $50 \%$ related to highways and streets. Other national estimates have also been reported of damage costs due to this phenomenon. Jones and Jefferson [3] claimed that shrink-swell related soil movements cost the British economy £3 billion over the previous 10 years. Charlie et al. [4] estimated damage due to expansive soils in Sudan at over $\$ 6$ billion annually.

Estimates of the swell expected to develop during wetting of unsaturated soil are usually based on laboratory tests carried out in consolidometer equipment. Undisturbed or compacted specimens, depending on the relevant field conditions, are placed in the consolidometer ring and wet while measuring vertical expansion. The tests are commonly performed according to ASTM standard D4546 [5] which requires that "the specimen is inundated with test water and the onedimensional wetting-induced swell or collapse strain is measured". This procedure undoubtedly provides an upper limit to the swell which may be expected under field conditions, and may be relevant to cases in which low lying areas are expected to be inundated as a result of a wetting episode. However, in other cases, wetting of the soil may result from less extreme conditions - for example, absorption of water from underlying, wetted layers, or soaking of the lower portion of a swelling layer and resultant upward wetting due to suction forces.
This paper presents results of a preliminary stage of a research project aimed at studying the flow and swell mechanism in unsaturated, compacted swelling clay. Swelling tests have been performed in a standard consolidometer, by wetting from the base of the specimen while applying different heads as well as by inundating the specimen in accordance with the ASTM standard. These tests indicate the significance of external hydraulic head on the resulting swell, and also provide clues as to the interaction between soil structure and the flow of water through unsaturated, swelling soil.

\section{The soil tested and testing procedure}

Clay specimens were prepared by remolding a natural, montmorillonite clay sampled from the Jezreal valley of northern Israel. Geotechnical characteristics of the material are presented in Table 1 .

Table 1. Indicative properties of clay tested.

\begin{tabular}{|l|l|}
\hline Fines content $(-200$ mesh) & $100 \%$ \\
\hline Specific gravity of solids $\left(\mathrm{G}_{\mathrm{s}}\right)$ & 2.72 \\
\hline Liquid Limit $\left(\omega_{\mathrm{l}}\right)$ & 75 \\
\hline Plastic Limit $\left(\omega_{\mathrm{p}}\right)$ & 28 \\
\hline USCS classification & $\mathrm{CH}$ \\
\hline Maximum dry density, Proctor $\left(\mathrm{kN} / \mathrm{m}^{3}\right)$ & 14.4 \\
\hline Optimum water content $(\%)$ & 25.7 \\
\hline
\end{tabular}


The material was air dried and crushed to an aggregate size of less than $4.75 \mathrm{~mm}$ (mesh \#4). Test specimens were prepared by mixing a known mass of air-dried soil with a pre-determined mass of water, to obtain a particular moisture content (usually 24\%). The material was then cured for 24 hours in a sealed, nylon bag, remixed, and placed loosely into the $63 \mathrm{~mm}$ diameter test ring which was outfitted with a collar extending above its top. The specimen was compressed, in load control, under a vertical pressure, to a nominal height of $21 \mathrm{~mm}$. Tests have been carried out on specimens prepared at different moisture contents and dry unit weights. This paper discusses tests in which the dry unit weight and the moisture content were nominally $14.4 \mathrm{kN} / \mathrm{m}^{3}$ and $24 \%$ respectively, i.e. Proctor maximum unit weight, and moisture content slightly below optimum. Following compression of the specimen, the ring was placed in the consolidometer under a specified vertical load; discussion here is limited to tests in which the applied vertical pressure was $30 \mathrm{kPa}$, equivalent to typical overburden applied by a pavement structure. The specimen was wetted from its base under a specified external hydraulic head defined as the driving water level relative to the base of the specimen. Water was supplied to the specimen from a water reservoir seated on a digital weight balance, and the reservoir weight was recorded with time, indicating the rate of inflow of water to the specimen during the swelling process. A schematic of the system is shown in Fig. 1.

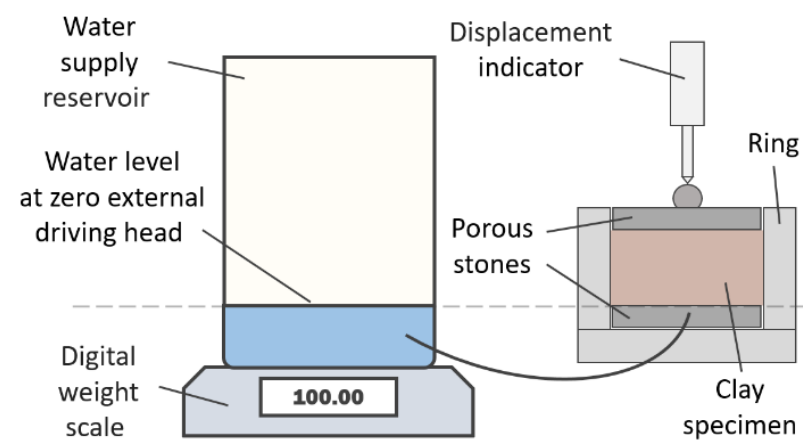

Fig. 1. Schematic of the test setup

\section{Results}

Fig. 2 shows the swell-time curves for three tests - one in which the specimen was inundated, and two in which external hydraulic heads of 0 and $40 \mathrm{~mm}$ were applied. Fig. 2 indicates the influence of external hydraulic head on swell, with inundation resulting in about $30 \%$ more swell, and at a much faster rate, than that developed when the externally applied head was zero. In the case of inundation, water enters the specimen by flow into the specimen from top and bottom, and is then quickly absorbed into the particle clusters and the particles themselves, causing rapid and large swell. When no external head is applied, water enters the soil only from its base, by suction alone. Consequently, the swell is significantly slower and may not reach the same amplitude, since continued penetration of the water may be blocked by decreased permeability or diffusivity in the wetted zone. The case of $40 \mathrm{~mm}$ applied head represents an intermediate case, where water penetrates into the soil as a result of both flow due to gravitational hydraulic gradient and advance due to suction.

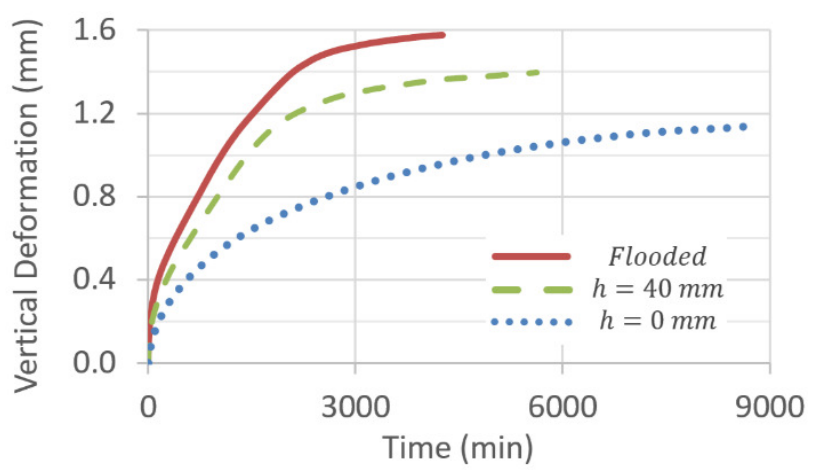

Fig. 2 Swelling curves with different external heads

While the swell curve is commonly shown relative to time, it is interesting to study the relationship between swell and the mass or volume of water entering the soil. This relationship is shown in Fig. 3 for the case of zero externally applied head, where $\delta_{v}$ is the vertical deformation and $\Delta M_{\mathrm{w}}$ is the mass of water infiltration.

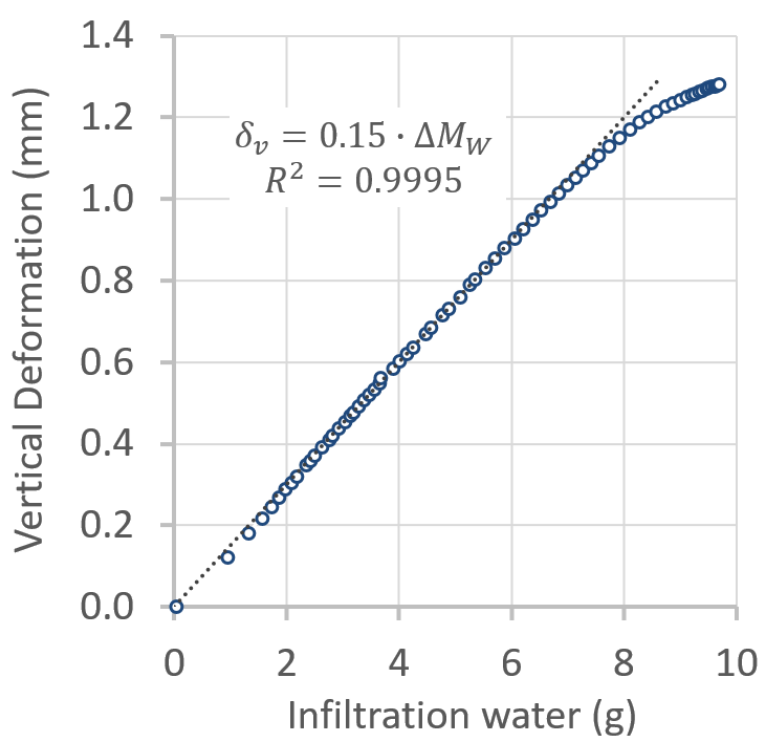

Fig. 3. Vertical deformation versus infiltration quantity, zero externalhydraulic head

There is seen to be a linear relationship between swell and amount of infiltrating water, until about $7 \mathrm{~g}$ of water enter the specimen. This infiltration results in an average degree of saturation in the specimen, $\mathrm{Sr}$, of about $82 \%$, as shown in Fig. 4. It is interesting, and perhaps relevant, that this degree of saturation is of the order at which air voids become occluded, and no longer continuous in the soil (e.g. Fredlund and Rahardjo, [6]).

Two additional, identical tests were performed in order to indicate the degree of repeatability, and to verify the reliability of the results shown in Fig. 3. Obviously, for the same initial moisture content and dry unit weight, the relationship between $\mathrm{Sr}$ and infiltration must be as shown in Fig. 4, regardless of external hydraulic head. 
The results of the additional tests are shown in Figs. 5 and 6 , the latter showing water inflow rate, both in terms of quantity of infiltration.

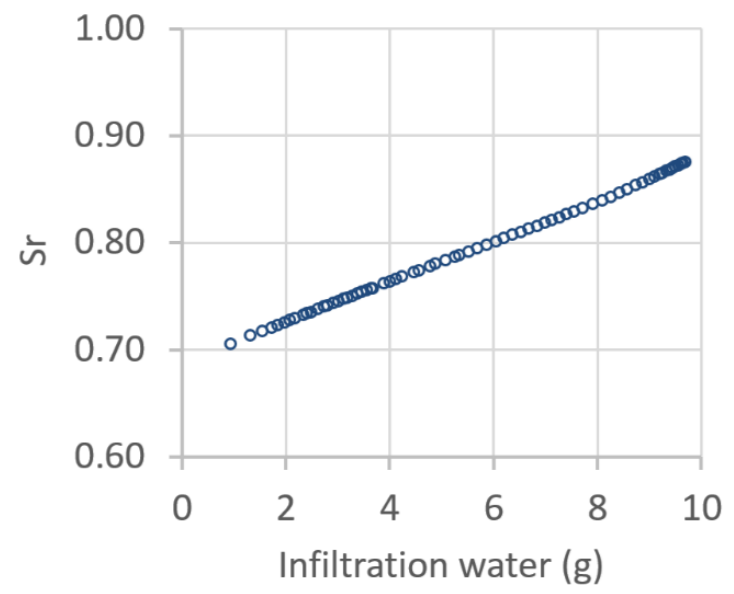

Fig. 4. Average degree of saturation, Sr, versus infiltration quantity, zero external hydraulic head

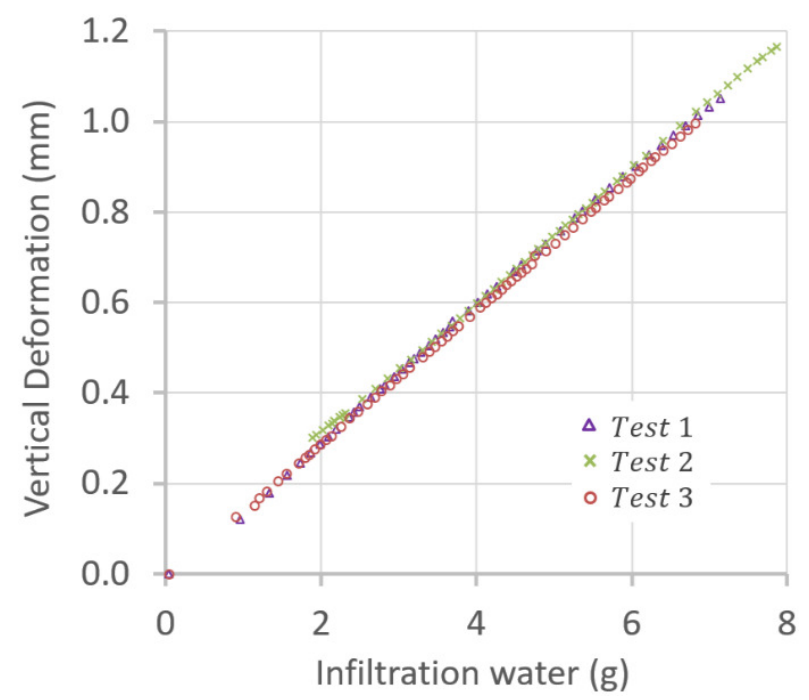

Fig.5. Replicate test results for swell versus infiltration quantity, zero external hydraulic head

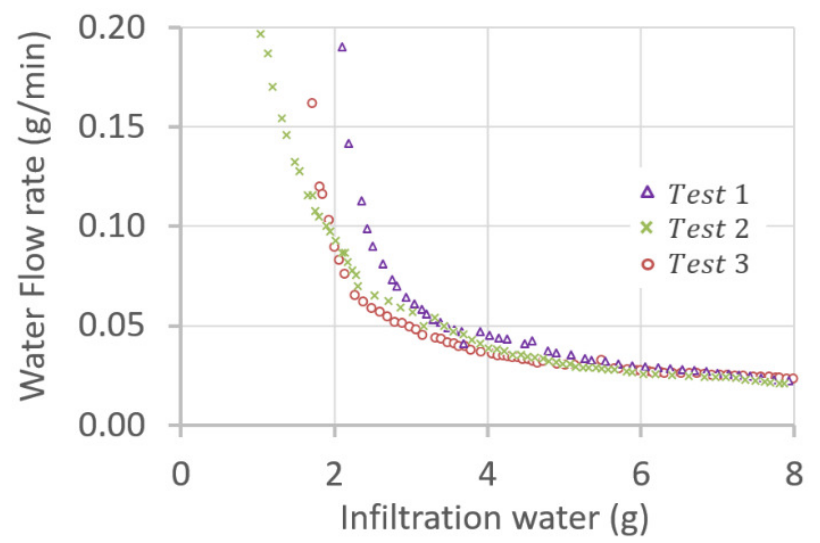

Fig. 6. Replicate test results for flow rate versus infiltration quantity, zero external hydraulic head
Excellent agreement is noted between the replicate tests, providing confidence for the repeatability of the observed relationships. In particular, the linear relationship relating swell to infiltration, which has not, to the authors' knowledge, been previously observed, may be useful in characterizing the flow and swelling mechanisms.

A set of tests has been carried out applying different external hydraulic heads: $-10 \mathrm{~mm}$ (i.e. the reservoir level was held $10 \mathrm{~mm}$ below the bottom of the specimen), 0 $\mathrm{mm}, 20 \mathrm{~mm}, 40 \mathrm{~mm}$ and $60 \mathrm{~m}$. The resulting swell is shown in Fig. 7 and the inflow rate is shown in Fig.8, both as a function of infiltration quantity. Fig.7 again shows linear relations between swell and infiltration quantity, but it is consistently noted that the gradient (i.e. the percent swell per gram of added water) decreases with increasing externally applied hydraulic head.

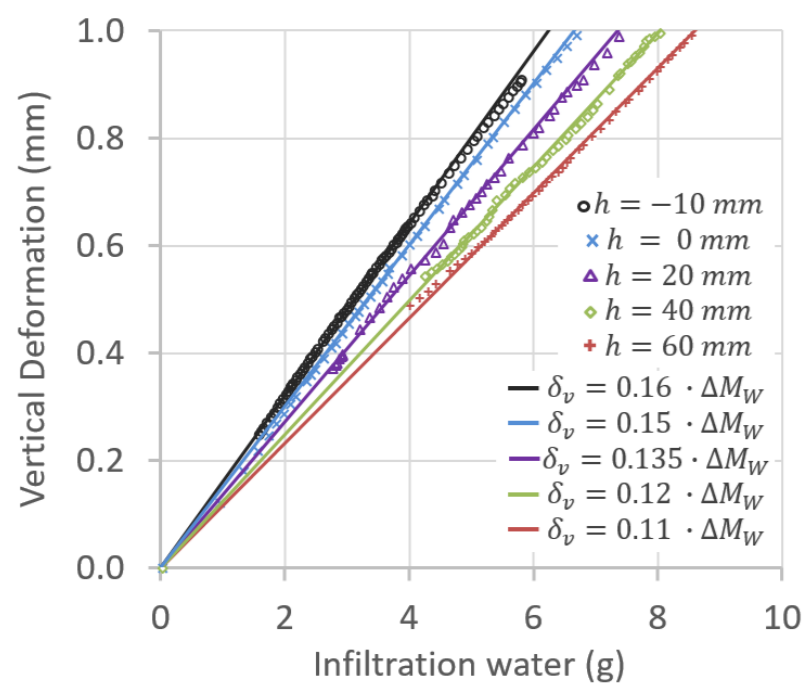

Fig. 7. Swell versus infiltration quantity for various external hydraulic heads

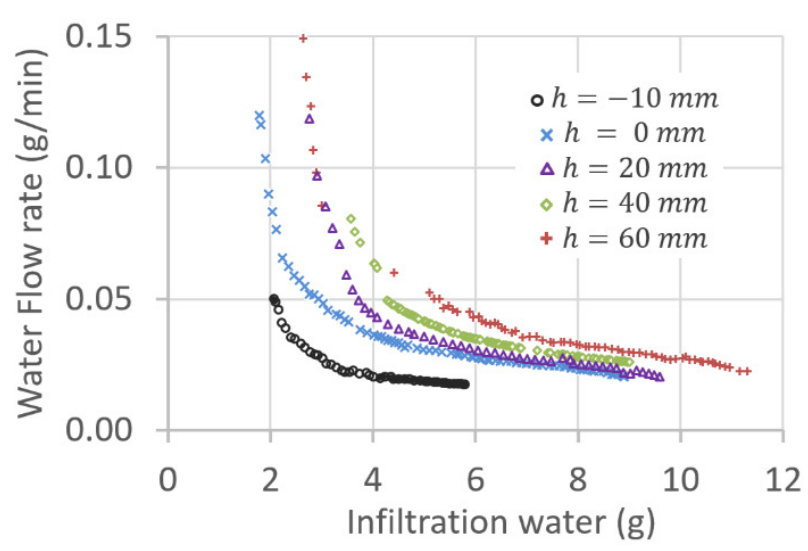

Fig.8. Flow rate versus infiltration quantity for various external hydraulic heads

The decrease in gradient with increasing external hydraulic head appears to have significant consequence in relating to the interaction between the structure of the 
clay and the flow and swell mechanisms. This phenomenon appears to be connected to the double porosity nature of the compacted clay which has been previously observed (e.g. Tovey et al. [7], Frydman and Weisberg [8], Miao et al. [9]) and discussed (e.g. Gens and Alonso [10], Baker and Frydman [11]). Miao et al. [9], for example, carried out mercury intrusion tests on Guanxi expansive clay, and obtained the pore size distribution curves shown in Fig. 9. This figure shows not only the double porosity nature of the clay, but also the observation that only the large pores compress with densification.

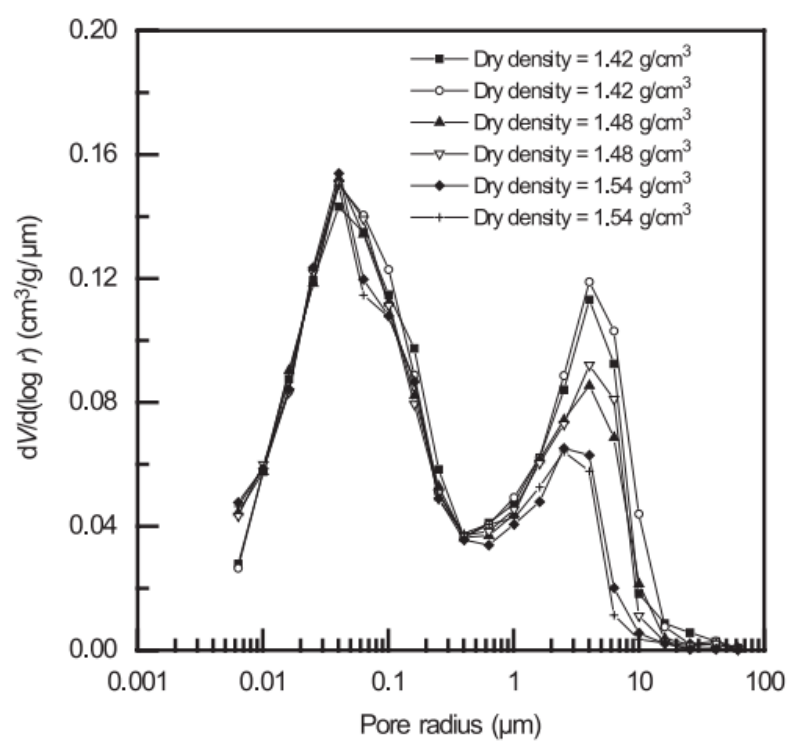

Fig. 9. Pore size distribution curves for Guanxi expansive soil using mercury intrusion (After Miao et al. 2007, presented with permission of the author).

It is usually assumed that the large pores (macro pores) exist between pods or aggregates of clay platelets and water, while the pore space within the pods is occupied by the micro pores. The pods are assumed to be saturated, with the water in them adsorbed to the platelet surfaces. Baker and Frydman [11] suggested that at moisture contents below optimum, the macro pores are essentially empty of water, and suction is due to adsorption forces in the micro pores. During compression to higher density, the volume of the saturated pods remains constant, while the macro pores compress, as seen in Fig. 9. It is suggested that adsorption of the water into the micro pores is the source of the swell. Fig. 8 shows that, as would be expected, the rate of flow into the specimen increases with the external hydraulic head. So, for example, with an external head of $60 \mathrm{~mm}, 3 \mathrm{~g}$ of water would flow in at the rate of about $0.1 \mathrm{~g} / \mathrm{min}$ whereas, for the same $3 \mathrm{~g}$ of infiltration, under zero external head the flow rate would be $0.05 \mathrm{~g} / \mathrm{min}-$ $50 \%$ of the former rate. It is, consequently, suggested that under the higher external head, a given quantity of inflow penetrates rapidly through the macro pores, with little absorption into the micro pores. Under zero external head, inflow of the same quantity of water occurs only due to absorption of water into the micropores, accompanied by swelling. Consequently, it is to be expected that a given quantity of infiltration will result in larger swell for lower external hydraulic head.

\section{Conclusions}

Tests on compacted specimens of swelling clay have shown that the degree and rate of swell increase with increasing externally applied hydraulic head. The influence of external hydraulic head may be of significance when estimating expected damage to roads, structures and infrastructure as a result of different wetting conditions. Not only may the common approach to design, based on inundation of test specimens, be economically wasteful, it may also result in damage due to differential movements where, for example, a road alignment includes sections which may be inundated and others where wetting will be a result of suction alone.

While higher external hydraulic head causes higher swell and at a higher rate, when considering the swell in relation to the quantity of water entering the soil, it is found that the swell per unit quantity of water inflow decreases with increasing externally applied hydraulic head. Consequently, a greater volume of water is required in order to develop the same swell that is obtained as a result of suction alone. This phenomenon has been explained in terms of the double porosity model for unsaturated clays.

It was found that swell is linearly related to the quantity of water entering the soil. This phenomenon may be useful in the development of a flow-swell model, adding to the relatively few models presently available for flow in swelling soil.

\section{References}

1. D.E. Jones, W.G. Holtz, Civ. Eng. ASCE, 43, 49-51 (1973)

2. J.X. Wang, Presentation, Louisiana Transportation Conf. (2016)

3. L.D. Jones, I Jefferson, ICE Manual Ch. C5 (2015)

4. W.A. Charlie, M.A. Osman, E.M. Ali, J. Const. Eng. \& Management, ASCE, 110, 359-374 (1984)

5. ASTM Standard D4546 (2014)

6. D.G. Fredlund, H. Rahardjo, Soil mechanics for unsaturated soils (John Wiley \& sons) (1993)

7. N.K. Tovey, S. Frydman, K.Y. Wong, Proc. 3rd Int. Conf. on Swelling Soils, 2, 45-54 (1973)

8. S. Frydman, E. Weisberg, Proc. Centrifuge 94 (Balkema), 669-674 (1991)

9. L. Miao, S.L. Houston, Y. Cui, J. Yuan, Can. Geotech. J. 44, 126-137 (2007)

10. A. Gens, E.E. Alonso, Can. Geotech. J. 29, 10131031 (1992)

11. R. Baker, S. Frydman, Engineering Geology 106, 26-39 (2009) 